Ayala Ardila, Richard. Ciborg-Ecología. La encíclica Laudatio Si en tiempos de indigencia y oscuridad. GeoGraphos [En línea]. Alicante: Grupo Interdisciplinario de Estudios Críticos y de América Latina (GIECRYAL) de la Universidad de Alicante, 2 de julio de 2017, vol. 8, no 98 p. 144-160. [ISSN: 2173-1276] [DL: A 371-2013] [DOI: 10.14198/GEOGRA2017.8.98].

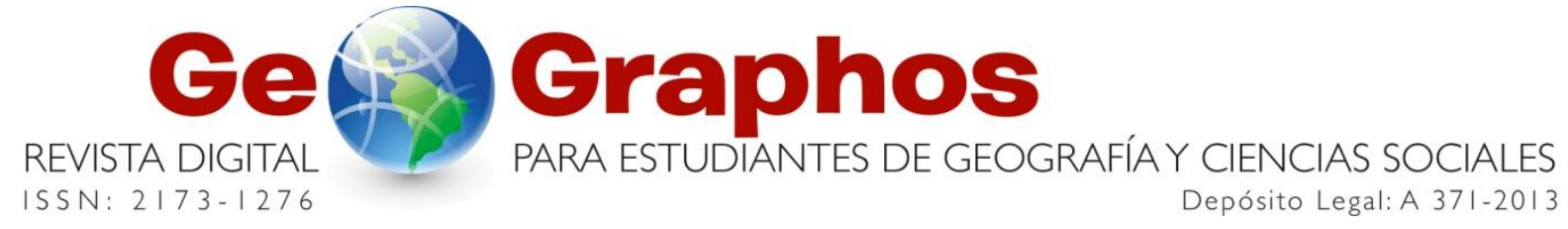

〈http://web.ua.es/revista-geographos-giecryal >

Vol. 8. $\mathrm{N}^{\mathrm{o}} 98$

Año 2017

\title{
CIBORG-ECOLOGÍA. LA ENCÍCLICA LAUDATIO SI EN TIEMPOS DE INDIGENCIA Y OSCURIDAD
}

\author{
Richard Ayala Ardila \\ Doctorado en Humanidades - Énfasis en Filosofía \\ Universidad d San Buenaventura. Sede Bogotá (Colombia) \\ Correo electrónico: rayala_1966@yahoo.es
}

Recibido: 11 de septiembre de 2016. Aceptado: 2 de julio de 2017 


\title{
RESUMEN
}

"Vivimos en tiempos de oscuridad o de indigencia" se dice para lamentar la muerte del hombre. Vivimos en el mejor de los mundos posibles, porque por primera vez es realmente factible la libertad, se dice para celebrar el comienzo de la "nueva era", aún en gestación. El Papa Francisco I, como era de esperarse, habla de oscuridad y de indigencia. Pero, también previsiblemente, él tiene esperanza y, obviamente, cree en el poder de la educación. De hecho, parece creer más en la educación que en Dios. Y si es más realista pensar en la escuela, y no en el templo, como lugar del cambio y por ende, de la esperanza, lo cierto es que entre mejor sea la educación menos razones tiene el Papa para soñar la utopía de la conversión ecológica. El hombre del futuro, en ciernes, no será humano. La escuela nace con la modernidad y es desde su origen una matriz ciborg. En la segunda mitad del siglo XIX nació su criatura y dese hace unas décadas, abrió los ojos.

Palabras clave: Ecología, filosofía, ciborg, Laudato Si, Heidegger.

\begin{abstract}
"We live in times of darkness or indigence" is said for mourn the death of man. We live in the best of all possible worlds, because for the first time is really feasible freedom, is said for to celebrate the beginning of the "new era", still in gestation. Pope Francis I, as expected, speaks of darkness and indigence. But, also predictably, he has hope, obviously, and he believes in the power of education. In fact, it seems, he believes more in the education than in God. And if it is more realistic to think in school, and not in the temple as a place of change and therefore of hope, the truth is that the better the education less reason does the Pope have to dream utopia of the ecological conversion. The man of the future, budding, will not be human. The school was born with modernity and the school is, since its inception, a cyborg matrix. In the second half of the nineteenth century, he was born his creature. A few decades ago, opened his eyes.
\end{abstract}

Keywords: Ecology, Philosophy, Cyborg, Laudato Si, Heidegger.

\section{RESUMO}

"Vivemos em tempos de escuridão ou indigencia" é dito para lamentar a morte do homem. Nós vivemos no melhor dos mundos possíveis, porque pela primeira vez é realmente liberdade viável, é dito para celebrar o início de uma nova era, ainda em gestação. Papa Francisco I, como esperado, fala de escuridão e indigência. Mas, também previsivelmente, ele tem esperança e, obviamente, acredita no poder da educação. Na verdade, ele parece acreditar mais na educação do que em Deus. E se é mais realista pensar na escola, e não no templo, como um lugar de mudança e, 
portanto,como um lugar da esperança, a verdade é entre melhor a educação menos razão tem o papa para sonhar sua utopia de conversão ecológica . O homem do futuro, brotamento, não será humano. A escola nasceu com a modernidade ea escola é , desde a sua criação, uma matriz cyborg. Na segunda metade do século XIX, nasceu sua criatura. Algumas décadas atrás, abriu os olhos.

Palavras-chave: Ecologia, filosofia, cyborg, Laudato Si, Heidegger.

\section{INTRODUCCIÓN}

Se nos dice: el capitalismo terminará por hacer inviable la vida en el planeta, incluyendo por supuesto la propia vida de la especie humana; frente a tal escenario apocalíptico, la especie está obligada a cambiar de forma sustancial muchas prácticas, concepciones e instituciones. Por ejemplo, la teología estaría obligada a: primero, repensar la premisa bíblica de "dominar la tierra", pues ésta ha sido un factor importante en la construcción de una visión depredadora de la naturaleza; segundo, considerar la posición individualista derivada del imperativo de "salvación del alma", para proponer una visión que incluya el compromiso ecológico; tercero, dialogar con las ciencias para alcanzar pensamientos universales y críticos; cuarto, dejar de tener los "ojos vendados" y de permanecer haciendo llamados ineficaces al deber ser. Y en ese contexto, se agrega, la encíclica Laudato Si ofrece alternativas teológico-antropológicas.

Pero, ¿algo de lo anterior es cierto? Por ejemplo, ¿jugó realmente la teología algún papel en el drama histórico dibujado en el párrafo anterior? De manera sucinta podrían recordarse estos lugares comunes: durante la época en la cual el pensamiento religioso dominó realmente la mente de los europeos, o sea en la Edad Media, apenas si puede hablarse de una concepción depredadora de la naturaleza; en las dos centurias durante las cuales se impuso el capitalismo como modo de producción planetario, siglos XIX y XX, la sociedad europea se distanció radicalmente de la teología, hablándose justamente de la muerte de Dios, la muerte de la metafísica y en general de la muerte de la tradición de pensamiento platónico-cristiano; en Europa la posición individualista no se encuentra históricamente asociada a "la salvación del alma" sino a la subjetividad cartesiana, la cual justamente puede vincularse con el momento en el cual Dios fue puesto entre paréntesis; por último, si la teología se limita a realizar meros llamados al deber ser no es porque se encuentre con los ojos vendados por culpa de sus presupuestos teóricos, sino porque tradicionalmente la iglesia católica ha sido una institución cómplice y corrupta. Y ¿hay en Laudato Si algún tipo de pensamiento, sea éste crítico o nuevo o fruto del diálogo con la ciencia en general o con algún tipo particular de ciencia? ¿Qué lo hace diferente a otro mero llamado al deber ser?

En el presente trabajo se desea mostrar otra forma de considerar la crisis. Diremos: el 
llamado "paradigma tecnocrático" está descrito en el mito de la caverna. Durante mil años, el modelo político-pedagógico de Platón fue una utopía, pero a partir del siglo XVI la sociedad europea realmente implementó tal modelo; la disposición académica de la sociedad se hizo realidad con el advenimiento de la clase y del currículo en la sociedad protestante, primero (Hamilton, 1991), y en toda la cristiandad, casi inmediatamente después. A partir de ese momento cartesiano (Foucault, 2009) o de ese poder pastoral del Estado (Foucault, 1988), hubo un lugar físico para realizar la Utopía platónica: la ciudad fue una República, lo cual no significa que la polis alcanzó el tamaño de una Nación, sino que la nueva estructura, a saber el Estado-Nación, se organizó según el modelo utópico de Platón. Así, Calvino fue el primer Rey Filósofo real y Ginebra la primera Utopía real. ¿Cómo encajan en esta historia Moro, Campanella y los socialistas utópicos que vinieron después? Bien se reconstruya el mundo en la cabeza a través de un método, una vez la crítica lo ha minado todo (Descartes), o se reconstruya el mundo, aunque éste tenga el tamaño de una pequeña ciudad, mediante el método de articular casa-taller-y templo (Calvino), lo decisivo es que el resultado aparece como producto de un plan (Método); en ese sentido, los utopistas del tipo "Thomas More" se diferencian simplemente porque sus productos son meramente mentales y porque en su tiempo, sus planes son juzgados simplemente como irreales.

¿Y Platón? ¿Y su República? La República de Platón o la Atlántida, a la cual diera lugar un mundo realizado según sus Leyes, constituían comunidades políticas utópicas en esencia, es decir, fueron concebidas para nunca ser realizadas, porque su creador sabía que eran eternamente irrealizables. Utopía realmente significaba "no lugar (topos)". O dicho de otra manera, el Estado-Nación fue el primer logro ciborg. Fue la matriz en la cual comenzó a gestarse la post-humanidad y lo post-humano. Recordemos: In illo tempore, la Ciencia fue la actividad por excelencia, la vida privada (Economía) y la vida pública (Política) se fundieron y el bienestar del organismo social (Estado-Nación)

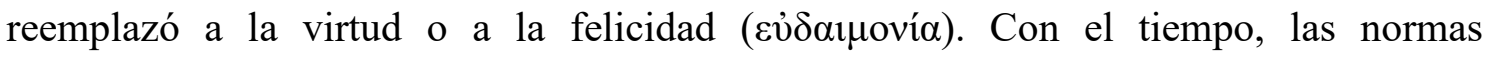
(Constituciones y leyes) ocuparon el lugar del Rey Filósofo. Tras tres siglos de Academia o de República, Europa sintió que se había equivocado. En la segunda mitad del siglo XIX, Europa experimentó un pathos nuevo: "Todo lo sólido se desvanece en el aire, todo lo sagrado es profanado" o "Los falsos valores de la moral tradicional deben ser trans-valorados". En esta situación de novedad, ruptura (Arendt, 1996), consumación (Heidegger, 2000), el intelectual humanista y sólo él, habló de crisis: Spengler (1966), Válery (1961), Huizinga (2007) (1972), Schmitt (1998). Los posthumanistas, hablaron diferente: dieron la bienvenida a lo sobre-humano (Nietzsche). También lo hicieron así los positivistas, porque todo lo habían objetivado, hasta el espíritu mismo (Comte, 1988) y los futuristas italianos (Marinetti, 1909), un poco después, porque celebraban el comienzo de la era ciborg.

En ese sentido, la Gran Guerra se limitó a exhibir públicamente en qué consistía el nuevo teatro: era una máquina de moler carne, si se lo juzgaba desde el lado humanista, esto es desde la perspectiva del nacional-socialista alemán sobreviviente, o era un nuevo 
campo de experimentación post-humana, si se lo comprendía desde la posición liberal soviético-americana. Desde la bomba atómica y la carrera espacial, la "nueva era" era ya un factum. Desde entonces, "La tierra es el astro errante"... Como una nave espacial sin tripulación. "Dirigirse hacia una estrella; sólo eso"...

Por supuesto, cuando Heidegger en el curso de una meditación tuvo este pensamiento "La tierra es el astro errante", el filósofo pensaba en otra cosa. Y claro, cuando al seguir el camino del pensar concibió otra idea: "Dirigirse hacia una estrella; sólo eso", Heidegger tenía en mente otra cosa. En ambos casos se trataba de algo muy semejante a lo que llevó a Hannah Arendt a decir Nada y Nadie. Heidegger decía: el Ser en el centro y en la proximidad, en la cercanía, el hombre, porque ese es su puesto ( $\sigma \tau \alpha \dot{\sigma} 1 \varsigma$ ). El hombre es propiamente humano cuando está en situación y la situación es con relación al centro (Claro del Ser). También decía, habitar, morar... ¿Cómo se pasa de la proximidad a la casa? Recordamos al lenguaje... Pensamos en el pensamiento como camino (ódós). Arendt decía: vivimos en una comunidad de laborantes (animal laborans), en medio de un híbrido entre lo público y lo privado, en un artificio automático creado por las manos humanas (Mundo). Es la desarticulación completa de La condición humana. Es el marchitamiento de La vida del espíritu. Uno y otra, Heidegger y Arendt, dicen lo mismo: el hombre está de espaldas al centro.

A ese SISTEMA dieron los apelativos de indigente (Heidegger) y oscuridad (Arendt). Actualmente se celebra esta condición de indigencia y oscuridad desde diferentes ópticas, nutridas todas de la Teoría General de Sistemas. El diagnóstico correcto dice: vivimos en la era del proceso o de los procesos. Lo cual significa: poco a poco realmente las fronteras de lo subjetivo y de lo objetivo se están desfigurando y poco a poco sólo va quedando eso: redes, nodos, flujos...SISTEMAS. El hombre (Sujeto) se diluye en el océano de cosas (Objeto), dando lugar a una nueva realidad: líquida (Bauman, 2003). Todo es vida... mera vida. Todo es metabolismo. Ya Husserl lo había expresado: "la vida no vive". "No hay vida en la vida". No hay vida del espíritu en la vida biológica.

Recordemos la oración: "no hay vida del espíritu en la vida biológica". Frente a ella se pude creer o no. Quienes creen en la verdad de la crisis se dividen en dos: de un lado se sitúan los que ven en la oración, la fuente del error. Allí, dicen, está la raíz del antropocentrismo maldito. Tal es la Ilusión trascendental en virtud de la cual el hombre estableció al sujeto de la dominación. Y sentencian, para sentir nostalgia por ese sujeto, por esa persona, por ese hombre, hay que ser un pensador aristócrata, un seguidor de Platón, o un vulgar creyente del Dios de la Cruz, pues el Cristianismo es mero platonismo para el pueblo. Quienes así opinan, frente a la crisis buscan una solución: pensar diferente, situar-se en un nuevo paradigma...Del otro lado están quienes sienten profundamente la oración: Valéry, Huizinga, Arendt, Heidegger... Escépticos, parecen decirnos: "nos encontramos Sin salvación". Justamente, porque entienden la crisis como crisis del humanismo o como fin del hombre. Finalmente, frente a la oración, se encuentran quienes no ven en la situación crisis alguna. Son herederos del sobre- 
humano de Nietzsche. Sloterdijk, por ejemplo, imagina a Heidegger, y con él a los herederos de Cristo, creyendo que el hombre de nuestro tiempo está de espaldas al fuego y al sol, al bien y al creador, por tanto, esperando el viraje salvador (Sloterdijk, 2011). Entonces, les pregunta: ¿Pero de dónde podría venir en el futuro un viraje más amplio, un viraje «fundamental», una diferencia radical? ¿Y si resulta que este viraje operado desde arriba no ha ayudado al mundo a detener su profana caída? ¿Y si también este giro devora a sus hijos? ¿Y si la perspectiva de Roma fue, para decirlo con dureza, el fascismo clerical? ¿Y la perspectiva de Ginebra la paranoia puritana? ¿Y la perspectiva de Wittenberg la desamparada religión privada que todavía baja la cabeza ante la peor autoridad?

Aún más radical, pregunta: ¿Qué es ese giro? ¿Qué significa la expresión «movimiento verdadero»? ¿Cómo se justifica este anhelo de un vuelco total? ¿No es hora de jubilar estos singulares fatales? ¿No surge también el peligro allí donde lo salvador se abre paso? Entonces nos cuenta una historia (Sloterdijk, 2011, p. 52-53): los marineros portugueses del siglo $\mathrm{XV}$, enfrentados al reto de partir sin posibilidad de regresar, decidieron aventurarse al mar abierto, decidieron abandonarse al movimiento, confiados en sus naves, en sus velas y en la esperanza; claro, una esperanza fundada, porque ellos intuyeron la existencia de un SISTEMA meteorológico que, de tener razón, les permitiría regresar a casa; porque lo vientos conocidos, al parecer, eran tan sólo una parte de los vientos realmente existentes, y porque, justamente, en esos vientos intuidosdesconocidos estaría la salvación, pues ellos virarían en sentido contrario, trayéndolos de regreso a casa. En el corazón del peligro estaba la volta do mar o eje del giro salvador. La moraleja es clara: adentrase valerosamente en ese océano sistémicoprocesual, con la esperanza de encontrar esa volta do mar con la cual la técnica se vuelva contra la técnica, el capital contra el capital, la guerra contra la guerra, en fin, se opere una revisión de las ciencias por las ciencias y una vuelta de los medios contra sí mismos.

En síntesis, se nos dice desde esta óptica, no hay crisis. El futuro, en el que ya vivimos, es ciborg (Haraway, 1995) y la forma realista de pensar las cuestiones medioambientales es la post-humanista, la cual excluye la perspectiva teológica, porque el hombre que creyó en Dios, en todas las formas posibles, ya murió. Los creyentes, en resumen, son meros sobrevivientes y tarde o temprano, ellos, sin el pan de la verdad, sin la luz de la espiritualidad, se extinguirán.

\section{LAUDATIO SI}

La encíclica hace un diagnóstico de la crisis ambiental y sobre ella elabora su propuesta. El texto nos informa de las gigantescas proporciones del daño ambiental, causado por el nuevo estado alcanzado en el sistema capitalista, al que citando a sociólogos contemporáneos llama "rapidación" (Francisco, 2015, p. 17) y cuyo origen puede encontrarse en esa forma de concebir la naturaleza como un sistema para ser analizado, 
comprendido y gestionad0 (p. 60) tal vez como algo esencial al "paradigma tecnocrático" (p. 79). Se nos habla de la híper-contaminación del aire, del mar y de los ríos, de la producción descomunal de basuras, la severa deficiencia en el suministro de agua para los más pobres y para ciertas regiones del planeta, de la inestimable pérdida de la biodiversidad y del deterioro de la calidad de vida humana, así como de la degradación social (p. 17-34). En resumen, el diagnóstico no aporta nada. A continuación nos ofrece una particular visión de la Biblia: el génesis nos enseña que no somos amos de la tierra, sino que la tierra pertenece a Dios y por él nos fue dada para ser cuidada y usada responsablemente; por eso, enseña Francisco, no hay en el texto sagrado lugar para sacar una visión antropocéntrica que dé al hombre la condición de amo. Nos dice, además, cuáles son las tres relaciones fundamentales, a saber, con Dios, con el prójimo y con la tierra. Sin embargo, nada nos dice del Dios de Israel, del prójimo como gentil y de la tierra como prometida, es decir, olvida que ese Dios eligió un pueblo y no pensó jamás en la humanidad como si de una familia única se tratara; o que la tierra para ser cuidada y labrada requiera ser primero merecida, alcanzada, conquistada; en síntesis, que la tierra no es el paraíso, ni el hombre de Israel es como San Francisco, un hombre en estado de inocencia primitiva (p. 52). Finalmente, cuando ese Dios habla como un terrorista islámico: «He decidido acabar con todos los seres humanos, porque la tierra, a causa de ellos, está llena de violencia (p. 56), el Papa ve allí una inocente moraleja: cuando la justicia no reina, la vida está amenazada.

En el tercer capítulo se considera la Raíz humana de la crisis ecológica. Vivimos en una nueva era, por entero, gobernada por la tecnología. Si bien es cierto, el inmenso poder dado por la tecnología a quienes tienen la capacidad de usarlo, puede ser bien o mal empleado, hay más razones para el pesimismo que para el optimismo, como se desprende, primero, de recordar el uso reciente de ese poder (Hiroshima), segundo, de saber de su concentración en pocas manos (multinacionales), tercero, de tener en cuenta "la falta [en la humanidad] de una ética sólida, una cultura y una espiritualidad que realmente lo limiten [al poder] y lo contengan en una lúcida abnegación” (p. 82), y por último, de considerar el efecto de la racionalidad cognitivo-instrumental que ha acostumbrado al hombre a tratar todo como si de un objeto disponible para su posesión, dominación y transformación se tratara (p. 83). El cuarto capítulo está dedicado a la propuesta, denominada Ecología Integral. Se trataría de una visión fundamentada en el presupuesto de que "Todo está conectado"; el tiempo y el espacio, las partículas subatómicas, todo (p. 107). Porque, la naturaleza está en nosotros y nosotros en ella, es decir, "estamos inter-penetrados con la naturaleza". Dada esta visión integral, la ecología integral debe contemplar también una ecología social (p. 111), una ecología cultural (p. 112) y una ecología de la vida cotidiana (p. 114), basada en el bien común como principio y en la idea directriz de haber recibido la naturaleza en préstamo, por tanto, para ser devuelta a la próxima generación (p. 123).

A partir del diagnóstico y de la propuesta, el Papa define algunas líneas de orientación y acción, lo cual ocurre en el capítulo quinto, y pone sus ojos en la educación, en el capítulo sexto. Las orientaciones son las siguientes: el planeta debe ser considerado 
como la patria o como la casa de toda la humanidad, en consecuencia, debe ser tratado como un proyecto común, lo cual debe traducirse en una política internacional (p. 127129) y local-nacional (p. 135-140), necesariamente condicionadas, y de manera esencial, por la preocupación medioambiental; la principal consecuencia de lo anterior sería subordinar la economía a la política y la política a la vida, especialmente a la calidad de la vida humana. Su esperanza educativa es esta: la vida contemporánea, gobernada por el "paradigma tecnocrático" (p. 155-156), como se expuso previamente, puede comenzar a superarse a través de una educación para la "ciudadanía ecológica" (p. 160), primero en la familia y luego en la escuela, pues en virtud de esta educación se puede alcanzar una espiritualidad ecológica o realizar una conversión ecológica, para lo cual San Francisco de Asís es un modelo (p. 146-166).

\section{LA LUZ DE LA FE. LA VERDAD DEL AMOR}

Martin Heidegger y Hannah Arendt coinciden en considerar al mito de la caverna de Platón como aquel texto en el cual se fijó por vez primera la clave del pensamiento occidental. Coinciden también al juzgar los acontecimientos de los últimos cien años (1850-1950) como señales del final de los tiempos: indigencia, se dice desde Heidegger, oscuridad, desde Arendt. Se viven, pues, tiempos de indigencia, tiempos de oscuridad. No obstante, maestro y discípula difieren en su comprensión de la historia, pues si el primero tiene en mente el pan de la verdad, a saber el pensamiento, Arendt se fija en la luz de la política, lo cual significa que para Heidegger el pensamiento occidental es como pez en dique seco, y para su discípula, la vida en las sociedades industrializadas es meramente la vida de animales laborantes (animal laborans) acontecida en un artificio creado tecnológicamente. El pensamiento inane y la política ausente son dos diagnósticos diferentes para la misma enfermedad: la muerte del hombre o el nacimiento de la post-humanidad. En el mismo sentido, el origen de Occidente en Platón señala con el índice el mismo fenómeno, a saber, el nacimiento del hombre del humanismo, aunque Arendt lo haga para juzgarlo o condenarlo y Heidegger para mostrar la necesidad de liberar a la Verdad del pesado yugo de la tecnocracia.

Tanto en La tradición y la época moderna, primero de sus ocho ejercicios sobre la política, como en el tercero, titulado ¿Qué es la autoridad. Arendt (1996, p. 101-153) expone su interpretación del mito de la caverna. Al parecer, Platón configuró su parábola de la caverna teniendo en mente el Hades de Homero. Usa las palabras

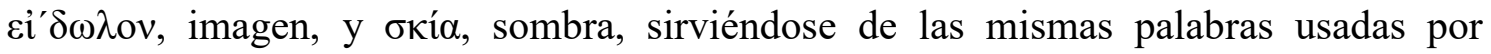
Homero para describir la vida tras la muerte en el mundo subterráneo... "como si el mundo subterráneo del hades hubiera emergido a la superficie de la tierra" (Arendt, 1996, p. 43). Con otras palabras, la parábola o alegoría comienza poniendo a Homero, y con él a la realidad, de cabeza: la esencia griega, a saber, la vida heroica, paradigmáticamente representada por la figura de Aquiles, es considerada como una muerte en vida; de cara al sol (Bien), fuente de todas las Ideas, energía nutricia para la ilusiva vida del espíritu, toda la vita activa, incluida la política, es una sombra, el pálido 
reflejo de otra realidad y otra vida, auténticas y verdaderas, en conjunto denominadas

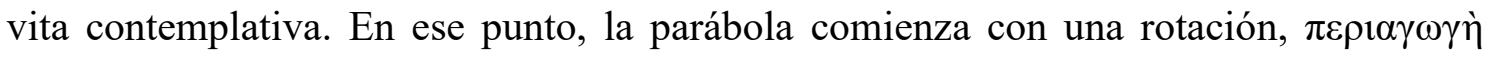
ö $\eta\rceil \varsigma \tau \tilde{\eta} \varsigma \psi v \chi \tilde{\eta} \varsigma$, cuando uno de los prisioneros gira su cuerpo y comienza el ascenso hacia el mundo de las ideas; luego continúa con la contemplación del firmamento límpido de las ideas eternas y concluye posteriormente con el regreso del filósofo al sombrío mundo de los asuntos humanos.

Y en el segundo texto, en el que encontramos una exposición más detallada y sobre todo, una interpretación del mito a partir de La doctrina platónica de la verdad, obra de su Maestro Martín Heidegger, para Arendt la autoridad es un concepto romano, ajeno a las experiencias políticas griegas, y fue justamente Platón, en La República, quien se acercó al concepto de autoridad cuando "enfrentó la realidad de la polis con un gobierno utópico de la razón, encarnado en la persona del rey-filósofo" (1996, p. 117), porque, como se comprende fácilmente, si el orden de los asuntos humanos es como el reino del conocimiento, la Verdad se impondría fácilmente en el espíritu de todos los hombres, a través del libre ejercicio de la razón; sin embargo, como es sabido, no todos los espíritus son matemáticos, de donde -es la opinión de Arendt- el "núcleo de la filosofía política de Platón" consistió en resolver este dilema: encontrar para la política algo coactivo y no violento, como la verdad (p. 118), es decir, hallar algo que se imponga a los hombres como lo hace la verdad en el orden del conocimiento, pero sin las dificultades presentes en el ejercicio de la razón, pues si bien todos la tienen, pocos tienen la capacidad de servirse correctamente de ella. ¿Cómo establecer una relación política análoga a la del médico y el enfermo o del general y su ejército o del capitán del barco y su tripulación, esto es, una relación en la cual el conocimiento muestra claramente la autoridad del gobernante? ¿O cómo establecerla en una relación semejante a la del amo y el esclavo, el padre y el hijo, el pastor y el rebaño, en la que la superioridad de uno sobre el otro es innegable y aceptada objetivamente en términos de autoridad? En opinión de Arendt, Platón jamás resolvió satisfactoriamente el problema (p. 119), pero encontró en el trabajo una poderosa analogía, que si bien no era como la de la Verdad en el conocimiento ni como la de la autoridad en las relaciones entre humanos naturalmente subordinados (el hijo frente al padre o el esclavo ante el amo), si era lo suficientemente eficaz en términos del problema planteado.

En efecto, así como en las artes y las artesanías las ideas o las formas gobiernan o someten o conducen o determinan la actividad, del mismo modo en la política el mundo de las ideas determina el reino de los asuntos humanos, si la comunidad decide realizarlas. O dicho nuevamente, del mismo modo que en la mente del artesano el objeto que desea fabricar preside toda la actividad, decidiendo los materiales adecuados, el tiempo de ejecución, las herramientas y la satisfacción frente al producto alcanzado, del mismo modo el cuerpo político podría actuar si previamente acuerda el tipo de organismo social que desea realizar (utopía). Esta analogía, en opinión de Arendt (p. 120-121), constituye el fundamento mismo de la parábola de la caverna.

En la interpretación de Arendt, "el firmamento de las ideas se extiende por encima de la 
cueva de la existencia humana y, por tanto, se puede convertir en su patrón” (p. 120), pero ello sólo ocurre cuando el filósofo regresa y desea introducir las ideas en la caverna. Con otras palabras, las ideas, que están ahí, para ser contempladas, son usadas posteriormente como normas para establecer la forma y el contenido de la vida en la caverna. Precisamente, este paso de lo uno, a saber, la contemplación o visión de las esencias verdaderas, a lo otro, o sea su aplicabilidad en el mundo de los asuntos humanos, es lo que Hannah Arendt debe a la interpretación de Heidegger. Ella encuentra genial el descubrimiento de su Maestro, a saber, la existencia en Platón de un desplazamiento desde la Belleza hacia la Bondad, o sea, un cambio de parecer, pues Platón, en opinión de Arendt, deja de considerar como idea suprema a la Belleza y pasa a poner en su lugar a la idea de Bien. En síntesis: "La función original de las ideas no era la de gobernar o disolver el caos de los asuntos humanos sino la de iluminar la oscuridad de esos asuntos con su brillantez esplendorosa" (p. 123), y Platón, creador del mundo de las ideas, advirtió la irrelevancia política de su creación y quiso posteriormente modificar su teoría de las ideas, movido por la necesidad política, o sea por su dilema; para hacerlo debió, por así decir, dar golpe de Estado a la Belleza y poner en su lugar al Dictador, esto es, al Bien. Pero, ¿es cierta la interpretación de Arendt?

En La doctrina platónica de la Verdad (2000), Martín Heidegger ve en el mito de la caverna un símil; para él, Platón ilustra plásticamente, mediante el símil de la caverna, la esencia de la formación, o con mayor propiedad, de la $\pi \alpha 1 \delta \varepsilon i ́ \alpha$ (p. 183). De este modo, el viaje del prisionero liberado hasta la superficie de la caverna y su regreso a la sombría estancia es una analogía para la transformación del hombre. A pesar de ello, afirma Heidegger, su interpretación remite a la doctrina de la Verdad en Platón, con lo cual se podría estar violentando el texto, lo que no ocurre, sin embargo, porque en el texto de Platón "se abre la mirada en dirección hacia una transformación de la esencia de la verdad" (p. 183). Con otras palabras, si en la interpretación de Heidegger no se cambia el tema del símil, la formación, es porque en Platón "la esencia de la verdad y el modo de su transformación hacen posible la formación en su entramado fundamental", o dicho nuevamente, porque Platón "encierra a la formación y a la verdad en una unidad

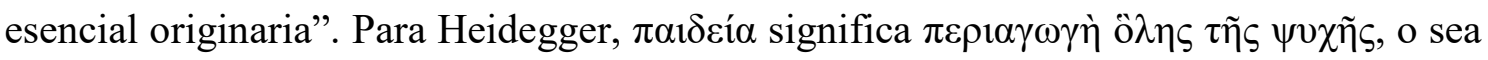
"lo que conduce a un cambio de dirección de todo el hombre en su esencia" (p. 182), lo cual acontece, "de cara a la adaptación, desde el ámbito de aquello que se presenta

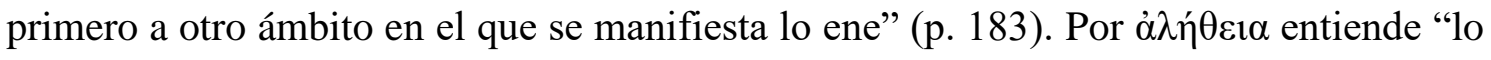
que se ha sustraído a un ocultamiento" (p. 187). Y en su opinión, el símil sólo puede ser comprendido si se advierte que la caverna es esencialmente un lugar para ocultar, recluir, guardar, esconder o cubrir, pero en el que, pese a ello hay lugar para la luz y los fenómenos de la visión. Por eso afirma: “¿qué otra cosa puede ser esa caverna subterránea más que algo abierto en sí, pero que, al mismo tiempo, al estar cubierto por una bóveda y rodeado de muros de tierra, permanece cerrado a pesar de la entrada?" (p. 187). En síntesis, la polis o el reino de los asuntos humanos es como el ente en general.

Sin embargo, y en ello consiste propiamente la interpretación de Heidegger, cuando Platón, por decirlo así, va hasta el mismo Sol (Bien), introduce una novedad: "la fuerza 
de la ilustración plástica no proviene de la imagen de clausura de la bóveda subterránea y de la prisión, así como tampoco de la visión del espacio abierto fuera de la caverna", sino del "papel del fuego, el reflejo del fuego y las sombras, la claridad del día, la luz del sol y el propio sol (p. 188). Con otras palabras, la fuerza metafórica y significativa está en la íóc $\alpha$ (p. 188). Así las cosas, sentencia Heidegger (p. 192), el "símil", en donde está expuesta la doctrina de Platón sobre la Verdad, no versa sobre la Verdad ( $\alpha \lambda \eta ́ \theta \varepsilon ı \alpha)$ sino sobre la Idea (i $\delta \varepsilon \dot{\varepsilon} \alpha$ ), o con mayor propiedad, versa sobre el proceso tácito mediante

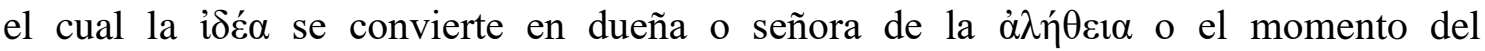

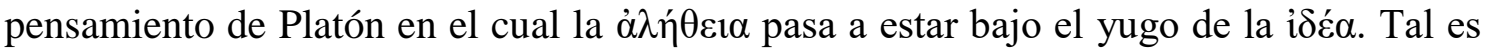
el núcleo de la interpretación y puede ser presentado nuevamente de este modo: el símil contiene una ambigüedad con relación a la esencia de la verdad; la ambigüedad se da porque allí nace una transformación de la esencia de la verdad y del lugar de la verdad, ello en virtud a que la verdad se torna ó $\rho \theta$ ó $\eta\rceil \zeta$, esto es, corrección de la aprehensión y del enunciado (p. 192). Por eso, en el símil "mientras se trata y se habla de la $\dot{\alpha} \lambda \hat{\theta} \theta \varepsilon 1 \alpha$ se está pensando y queriendo decir, y considerando como normativa, a la ỏ $\rho$ ó $\tau \eta \varsigma$, y todo ello en un mismo y único paso del pensamiento" (p. 193).

En conclusión: Arendt celebra la interpretación de la parábola realizada por su maestro; la califica de notable. Para ella, allí Heidegger muestra con toda claridad la función genética de la parábola: nace la verdad como adaequatio intellectus et rei. También nacen la metafísica y el humanismo, podemos agregar, pues Heidegger afirma: "El comienzo de la metafísica en el pensamiento de Platón es al mismo tiempo el comienzo del humanismo" (p. 196). Sin embargo, Heidegger, en opinión de Arendt, "no es consciente del contexto político en que aparece la parábola" (Arendt, 1996, p. 302). Pero, ¿es esto cierto?

\section{CIBORG-ECOLOGÍA}

En cierta ocasión Heinrich Blücher, segundo esposo de Hannah Arendt, dijo: los pesimistas son cobardes y los optimistas son imbéciles. Frente al apocalíptico diagnóstico ambiental los optimistas reaccionan profesando su fe en la educación ambiental; y en este, como en todos los casos, el escepticismo aparece como una salida ante el incómodo dilema, no obstante, el escepticismo mismo ha devenido en mero lugar común y no realmente en un lugar o espacio o topos común, es decir, de encuentro entre un YO y por lo menos un otro (Tú). Para intentar hacer de este texto un verdadero lugar común, nada como contar una historia.

Como saben quienes aman a Hannah Arendt, su compañero, Heinrich Blücher, descansa en paz en una modesta tumba ubicada a escasos cien metros de la biblioteca del Bard College. De hecho, ella misma reposa junto a su esposo. Pues bien, un día, casi accidentalmente, Peter Sloterdijk llegó hasta sus tumbas (Sloterdijk, 2011). Y allí tuvo una meditación bárbaro-tecno-germánica. Pensó en el amante de Hannah Arendt: el Maestro Martin Heidegger. Recordó que éste último se había hecho enterrar en el 
cementerio de Meßkirch. En su mente se superpusieron las imágenes de los dos profesores universitarios enterrados al interior de la Academia situada en las márgenes de una metrópoli (New York) y la del Maestro en un cementerio casi rural. Los primeros lo hicieron pensar en el campus como representación por excelencia de la Academia: la Isla de los Bienaventurados en medio del mar de la política o de la Polis. Y allí estaban Blücher y Arendt, pero en un islote de muertos, pues yacían junto a antiguos presidentes del College, en ese inusual cementerio de profesores.

El segundo (Heidegger) lo hizo pensar en el gusto por la marginalidad provinciana, profesado por Her Professor. De nuestra parte imaginamos un relámpago relevador cayendo sobre la humanidad del caminante alemán en su periplo neoyorquino; entonces, Sloterdijk se preguntó: ¿Cómo es posible un académico ermitaño? ¡Hasta para morir, Arendt eligió la ciudad (campus), Heidegger el campo (camposanto rural)! Y la historia del pensamiento occidental se abrió para Sloterdijk: una prístina línea recta vinculó a todos los filósofos de Platón a Heidegger; Heidegger no es un pensador de escenario o tribuna (2011, p. 12), no se sitúa en el altar mayor sino en la sacristía, no es sacerdote sino asistente, no es Führer sino asesor. Heidegger cree en el advenimiento de la sacristía. Algún día los acontecimientos elevarían la sacristía al estatus de aula y al aula a la categoría de cancillería lógica del Reich (p. 13). Y cuando ello ocurra, ¡la misa católica será nuevamente tragedia, canto del macho cabrío! ¡De nuevo la carne y la sangre! ¡Sacerdote de la nueva era! He ahí -sentencia Sloterdijk- la clave de su filosofía (la de Heidegger) y de la filosofía toda, porque desde Platón todos los filósofos rompieron con el teatro. ¡Ninguno fue un pensador de escenario! Platón por lo menos supo lo que hacía, porque su decisión obedeció a un hecho histórico: en el año 386 a.C. el parlamento ateniense promulgó una ley en virtud de la cual se podía volver a representar una tragedia exitosa en alguna versión anterior del festival anual de teatro dionisiaco, con lo cual se violaba una norma antigua y se daba comienzo a la transformación de la Religión en arte o en fenómeno estético. Con este hecho mediático los políticos atenienses asumieron la incierta y potencialmente peligrosa decisión de cambiar la síntesis tonal de la ciudad, esto es, asumieron la responsabilidad por la posible desintegración mito-musical de la polis y por los desequilibrios morales a que ello diera lugar (p. 16). La fundación de la Academia -sentencia Sloterdijk- fue un acto político conservador: "Lo que hoy llamamos filosofía es directa e indirectamente una consecuencia de la ofensiva de Platón contra los nuevos medios. Supone la invención de la escuela en el espíritu de la resistencia contra el teatro sin restricciones".

Si la anterior historia de la filosofía es falsa o verdadera poco o nada importa. Hace algunos años, Derrida miro-se gato y nos contó la suya (Derrida, 2008). Y Hannah Arendt hizo lo propio sobre la base del conflicto entre filosofía y política. Lo realmente importante es tener siempre presente el mito de la caverna -la historia de Cristo ascendiendo a la cruz de la superficie de la caverna, para luego, de regreso, resucitado al mundo de los prisioneros, encarnar al hombre de la inquietud o representar el drama del hombre devenido problema, o sea el misterio de ser piedra viva- para experimentar en la lectura de estas interpretaciones de la historia de la filosofía cómo Platón despliega 
toda su ironía.

En la historia contada por Sloterdijk, por ejemplo, Platón acababa de regresar de su estancia con los pitagóricos, aquellos lógicos piadosos, cuando en Atenas se tomó la nefasta decisión de desacralizar al teatro, es decir, a la religión, y entonces, teniendo en mente y como ejemplo la vía correcta de la enseñanza pitagórica, decidió democratizar la práctica pitagórica poniéndola a disposición de quienes optaran al título de Academo, y mejoró la acción pedagógica de Pitágoras, pues mientras ésta permanecía alejada de la vida normal u ordinaria, la suya, (La de Platón) era más justa, por ser más política, más cercana a la realidad. Sloterdijk sintetiza: "En su viaje de regreso, Platón concibió una idea cargada de consecuencias: en vez de secta, debe haber escuela" (p. 18). Ahora imaginemos a Platón hablando ante el parlamento ateniense, tras la injusta muerte de Sócrates. Platón declara públicamente apartarse de la vida política para dedicarse a la Academia. En realidad tiene un plan maquiavélico: ¡Un día, en nombre de la Verdad, la secta de los maestros tomará el poder! Aparentemente, se retira. En realidad, Platón introdujo la Verdad en la Ciudad dentro de la escuela, tal cual hicieron los aqueos, al regalarle a los moralmente ejemplares habitante de Ilión el famoso caballo de Troya. Con ciencia devolvió a la ciudad la cicuta recibida por la filosofía. Con episteme mató la vida y vengó la muerte del Filósofo.

No obstante, ¿qué sería de la ironía sin la gravedad? Por eso Sloterdijk declara: la filosofía como poder de la escuela es un nuevo medio de la teofanía; "la filosofía era decididamente no-teatro; su programa era no-representación y no-exhibición del dios en el escenario; su ambición era proponer al dios un canal purificado, interiorizado y logificado para epifanías más sutiles. Tal es la razón de que los filósofos -hasta Heidegger - suelan ser, como decía, naturalmente pensadores en el no-escenario, pues mientras tengan algo que aportar a su especialidad, serán declarada y felizmente académicos. Si alguien preguntase qué pueda ser una academia feliz, la respuesta sería: no otra cosa que una escuela animada del convencimiento de ser el espacio de aparición preferido del dios, el templo mejorado, el oráculo esclarecido, el teatro superado, el misterio precisado" (p. 18). A la elocuencia del ágora, Sloterdijk opone el silencio de la Academia o del monasterio. A las esplendorosas gestas del teatro de la política, Sloterdijk contrapone la ausencia de Dios en la praxis escolar, o en el mejor de los casos, su mínima expresión en la vida interior. De ahí su sentencia: "el rumor de una doctrina no escrita de Platón tiene consistencia; se trata de la discreta competencia teofánica de la labor académica" (p. 19). Y para nadie es un secreto que durante el siglo XVI se cambió el centro de gravedad, desplazando a Dios y poniendo en su lugar al hombre, llamado desde entonces sujeto y cogito. Nacieron entonces la pedagogía y la ciencia, modernas; el Estado y la Ciudad, propiamente tales; las ideas y los valores, objetivos.

Pero, ¿nos hemos preguntado cómo se hace realidad una Idea o se materializa un valor? Es decir, después de esa suplantación de Dios, realmente unas personas pudieron posar sus pies sobre la superficie lunar y otras dividieron-fusionaron átomos, siendo estas 
hazañas impensables sin ese giro copernicano gravitacional. Después de esa suplantación de Dios, realmente la ética o moral perdió todo su valor en manos del único valor otorgado al dinero; desde entonces, realmente el tiempo fue dinero y el dinero un momento de reificación en el incesante proceso de acumulación de capital. Desde entonces, realmente las fronteras se van disolviendo y poco a poco sólo van quedando procesos, redes, sistemas; realmente el sujeto racional fáustico-prometeico se ha ido humanizando, sensibilizando, ablandando, hasta: sentirse incapaz de condenar y castigar (justicia restaurativa; derecho penal abolicionista); alimentarse sin culpa o nutrirse sin cargos de conciencia (declaración universal de los derechos de los animales; la naturaleza es persona o sujeto de derechos); discernir entre realidad y apariencia (física cuántica); o simplemente ser algo, porque se descubrió que todo era mera palabra (Nietzsche: la verdad son metáforas desgastadas; Marx: la verdad era ideología), porque el pensamiento crítico venció a su enemigo tradicional y ahora quedó condenado, como Sísifo, a la deconstrucción (Toma un concepto en el valle y mientras asciende en la cada vez más fácil tarea deconstructiva, la roca se deshace hasta encontrar el prejuicio fundacional: cada palabra es una cara del antropocentrismo original o una arista de la tesis de la excepcionalidad del hombre).

Así como Sloterdijk le niega a Platón su misticismo, le niega a Heidegger su poder. ¿Cuál? Heidegger es el pensador de la crisis o del fin. Y en este punto, la ironía consiste en la esclarecida lectura de la obra de Heidegger, hecha por Sloterdijk: la historia de la religiosidad o espiritualidad de Occidente es la historia de la desacralización del centro colectivo y el surgimiento de otros espacios de sacralización, como la iglesia católica, la escuela, el estado, la obra de arte, finalmente, la intimidad de las personas. En este escenario se destacan la música de Wagner y la filosofía de Nietzsche. Justamente, Nietzsche es el único filósofo no-filósofo, porque él, lejos de estar detrás del escenario, es el escenario. De ahí su locura. El cuerpo-mente de Nietzsche fue el lugar de la gigantomaquia. Heidegger, por el contrario, vivió a salvo, porque siempre estuvo encerrado "en una disciplinada y atroz normalidad". Realizado este diagnóstico negativo, ontológico-filosófico, "Heidegger no es un pensador en el escenario", Peter Sloterdijk, lector onto-antropológico del Dasein de Heidegger, presenta una determinación positiva de la carencia: "Heidegger es el pensador en el movimiento" (p. 20). Que ese movimiento es el pensar mismo en cuanto experiencia o realidad actualizada no lo dice Sloterdijk. Como tampoco dice nada de la relación poética entre ese movimiento y el amor.

\section{CONCLUSIÓN}

En nuestra opinión, el tono universalista de Laudato $S i$ le resta fuerza al dogma platónico oculto en el mensaje cristiano: la fe no es una creencia sino el fruto de la Verdad-Amor como experiencia. El amor es la norma introducida por el Filósofo de Platón. El amor es la vida del espíritu introducida en la vida biológica por el hombre de la Cruz. Si no se insiste en el poder de transfiguración o transformación propio del 
amor, el principio "Todo está conectado" resulta demasiado próximo a los pensamientos propios de la Teoría General de Sistemas, el holismo, el pensamiento complejo, en resumen, a todo ese imaginario contemporáneo en el cual Sujeto y Objeto se funden en la nada llamada SISTEMA o PROCESO.

Por la misma razón, el núcleo pedagógico de la Teoría de Platón pierde todo su fundamento, en consecuencia, la esperanza de conquistar la conversión ecológica desde la educación ambiental o educación ecológica deviene mero llamado al deber ser o simple utopía. A esta educación, llave del futuro y cofre de la esperanza, le están faltando el giro, la dialéctica didáctica y la revelación. Con otras palabras, ¿hay razones

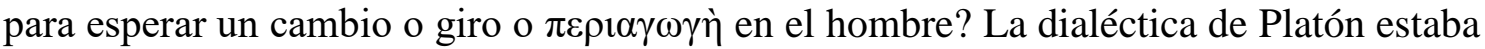
concebida como escalera del iniciado y aun así el Maestro no garantizaba el salto a la contemplación. ¿Hay razones para la esperanza? La educación ambiental es en Laudato $S i$ un modesto lugar para la teofanía: celulosa para la inanidad, frágil e incierta vela encendida para la oscuridad.

La Justicia en Sócrates, la Verdad en Platón y el Amor en Cristo son eternamente paradigmáticos para el hombre del humanismo. Hoy en día, más que nunca, la lógica de la contradicción auto-constitutiva es necesaria. Los críticos de la tradición sentencian: vivimos, por desgracia, presos en una gramática cuyo presupuesto es una ontología insostenible, a saber, la tesis de la excepcionalidad del hombre. La tradición platónicocristiana, continúan los críticos, estableció una dualidad insuperable: Tú y YO; de un lado, TÚ, lo dado, lo objetivo, la cosa, incluida la naturaleza y hasta el propio cuerpo; del otro, YO, lo auto-constituido, lo auto-fundado, el YO narcisista, egoísta, poderoso, dominante, amo del tú y del yo, un cogito ilusivo e irreal. Pero los críticos no han comprendido que el Tú y el YO desaparecen en la comunión: TUYO.

Que para el hombre del humanismo platónico-cristiano TODO se resuelve en el misterio de esa simple oración "TUYO", o su equivalente, "AMÉN", no es algo evidente. Para saberlo se necesita experiencia en la práctica del amor como misterio. Sólo así la palabra "tuyo" o la palabra "amén" queda ahí en la boca, como fruto en el árbol. Sólo así se comprende la fenomenología en virtud de la cual la carne se ilumina o muestra o exhibe o expone, mientras el espíritu se oscurece u oculta o esconde o protege: $¡ \dot{\alpha} \lambda \eta \dot{\eta} \theta \varepsilon 1 \alpha$ es Amor! Porque quien ama es un Dios caído. Ahí, en el mundo, caído en la conciencia, en el lenguaje, en la representación, ese Dios sólo conoce el camino de la cruz, del ascenso, del viacrucis. Heidegger lo llamó yugo, también, señora y dueña. Dijo: la Verdad quedó atada al bien por la Idea (i $\delta \varepsilon \dot{\varepsilon} \alpha$ ). Fundó la Academia, descubrió la pedagogía, como actividad de raíces amargas y dulces frutos. Porque el hombre es un árbol nutrido por el Bien (Luz), cuya savia es la Verdad (episteme) y cuyo único fruto es el Amor. Claro, ese hombre, que es el hombre del humanismo, que reconocemos en San Francisco de Asís o en la Madre Teresa de Calcuta, siempre fue, es y será una excepción. 


\section{BIBLIOGRAFÍA}

Arendt, Hannah. Entre el pasado y el futuro. Ocho ejercicios de reflexión política. Barcelona: Península, 1996.

Bauman, Zigman. Modernidad líquida. Buenos Aires: Fondo de Cultura Económica, 2003.

Comte, Auguste. Discurso sobre el espíritu positivivo. Madrid: Alianza Editorial, 1988.

Derrida, Jacques. El animal que luego estoy si(gui)endo. Madrid: Trotta, 2008.

Foucault, Michel. El sujeto y el poder. Revista Mexicana de Sociología, 1988, p. 3-20.

Foucault, Michel. La hermenéutica del sujeto. Buenos Aires: Fondo de Cultura Económica, 2009.

Francisco I. Carta encíclica LAUDATO SI. El Vaticano: Tipografía vaticana, 2015.

Hamilton, David. Orígenes de los términos educativos "clase" y "currículum". Revista de Educación, 1991, p. 187-205.

Haraway, Donna. Ciencia, cyborgs y mujeres. La reinvención de la naturaleza. Madrid: Cátedra, 1995.

Heidegger, Martin. La doctrina platónica de la verdad. En M. Heidegger, Hitos. Madrid: Alianza Editorial, 2000, p. 173-198.

Huizinga, Johan. Homo ludens. Madrid: Alianza Editorial, 1972.

Huizinga, Johan. Entre las sombnras del mañana. Diagnóstico cultural de la enfermedad de nuestro tiempo. Barcelona: Península, 2007.

Schmitt, Carl. El concepto de lo político. Madrid: Alianza Editorial, 1998.

Sloterdijk, Peter. Sin salvación. Tras las huellas de Heidegger . Madrid: Akal, 2011.

Valéry, Paul. Política del espíritu. Buenos Aires: Losada, 1961. 
(C) Copyright Richard Ayala Ardila y Revista GeoGraphos, 2017. Este artículo se distribuye bajo una Licencia Creative Commons Reconocimiento-NoComercial 4.0 Internacional.
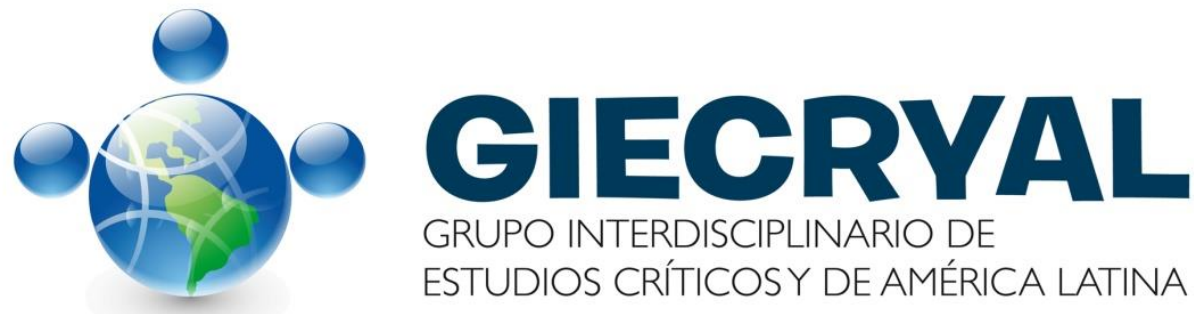

GRUPO INTERDISCIPLINARIO DE

ESTUDIOS CRÍTICOSY DE AMÉRICA LATINA 